\title{
Simulação do Processo de Soldagem Elétrica por Centelhamento de um Aço para Trilhos Ferroviários. Parte 2: Análise Dilatométrica e Numérica
}

\author{
Rodrigo Rangel Porcaro ${ }^{1}$ (D), Francisco Célio de Araújo ${ }^{2}$ (D), Leonardo Barbosa Godefroid ${ }^{1}$ (D), Geraldo Lúcio de Faria ${ }^{1}$ (D), Luiz Leite da Silva ${ }^{3}$ (D) \\ ${ }^{1}$ Universidade Federal de Ouro Preto - UFOP, Rede Temática em Engenharia de Materiais - REDEMAT, Ouro Preto, MG, Brasil. \\ ${ }^{2}$ Universidade Federal de Ouro Preto - UFOP, Programa de Pós-Graduação em Engenharia Civil - PROPEC, Ouro Preto, MG, Brasil. \\ ${ }^{3}$ Centro de Desenvolvimento da Tecnologia Nuclear - CDTN, Comissão Nacional de Energia Nuclear - CNEM, Belo Horizonte, MG, Brasil.
}

Como citar: Porcaro RR, Araújo FC, Godefroid LB, Faria GL, Silva LL. Simulação do processo de soldagem elétrica por centelhamento de um aço para trilhos ferroviários. Parte 2: análise dilatométrica e numérica. Soldagem \& Inspeção. 2020;25:e2533. https://doi.org/10.1590/0104-9224/SI25.33

\begin{abstract}
Resumo: Trilhos longos soldados por centelhamento elétrico (Flash Butt Welding - FBW) apresentam características desejáveis do ponto de vista do comportamento dinâmico da via, no entanto, as soldas são regiões de descontinuidade estrutural e mecânica onde se originam tensões residuais, e que estão associadas a falhas prematuras por fadiga. Ensaios de dilatometria foram empregados para simular os efeitos do tamanho de grão austenítico sobre a evolução microestrutural pós-soldagem. Simulações numéricas termomecânicas, não-lineares, no domínio do tempo, pelo Método dos Elementos Finitos (MEF), foram empregadas para avaliar os efeitos de modificações de parâmetros do processo de soldagem sobre as tensões residuais. Os resultados apresentados permitem compreender os mecanismos das alterações morfológicas da perlita na Zona Termicamente Afetada (ZTA) em termos de transformações de fases e podem ser utilizados para sistematicamente orientar mudanças nos parâmetros do processo ou controlar a taxa de resfriamento de modo a obter melhores condições metalúrgicas/mecânicas. Ademais, os resultados dos modelos numéricos mostram como a adoção de ZTA estreita influencia nas taxas de resfriamento e no desenvolvimento de tensões residuais em regiões críticas do componente.
\end{abstract}

Palavras-chave: Soldagem por centelhamento; Trilhos ferroviários; Dilatometria; Metalurgia da soldagem, Método dos elementos finitos.

\section{Simulation of Flash-Butt Welding Process of a Railway Steel. Part 2: Dilatometric and Numerical Analysis}

\begin{abstract}
Long rails, welded by the Flash-Butt Welding process present desirable characteristics concerning the dynamic behavior of the track, however flash-butt-welded joints are regions of structural and mechanical discontinuity where high residual stresses originate, and, consequently, premature-fatigue failures may take place. This paper employs dilatometric analysis to simulate the austenitic grain size effects on the postweld microstructural evolution. Finite Element Method (FEM) is used to carry out transient, physically non-linear thermo-mechanical analyses to evaluate the effects of the welding parameters on residual stresses. The results allow understanding the mechanisms associated with the morphological changes of the pearlite in the HAZ in terms of phase transformation and can be used to systematically guide changes in the process parameters or to control the cooling rate in order to obtain better metallurgical/mechanical conditions. In addition, from the results of the numerical models, it is demonstrated how the adoption of narrow HAZ influences cooling rates and the development of residual stresses in critical regions of the welded component.
\end{abstract}

Key-words: Flash butt welding; Rail steels; Dilatometry; Welding metallurgy, Finite element method.

\section{Introdução}

A microestrutura dos aços utilizados em trilhos ferroviários é formada principalmente por perlita [1]. O aumento da dureza superficial reduz o desgaste no boleto dos trilhos ferroviários, sendo a redução do espaçamento interlamelar o principal mecanismo desenvolvido para esse fim, obtido por tratamentos térmicos e/ou adição de elementos de liga [2].

Em trabalho anteriormente publicado nesta revista, Porcaro et al. [3] apresentaram detalhada caracterização estrutural e mecânica de trilhos ferroviários perlíticos soldados por centelhamento elétrico. Verificou-se, por meio dos resultados da análise morfológica da perlita, em toda a extensão da ZTA, que os ciclos termomecânicos do processo de soldagem promovem a variação do tamanho de colônias, espaçamento interlamelar e esferoidização parcial da cementita, com significativa variação de microdureza. Naquela ocasião, assim como em trabalhos anteriores [4], foi sugerida a utilização de ensaios dilatométricos para entender a evolução microestrutural do aço quando submetido aos ciclos térmicos do processo de soldagem. A falta de conhecimentos sobre os 
mecanismos metalúrgicos envolvidos na evolução estrutural da perlita após a soldagem por centelhamento também foi abordada por Nishikawa e Goldenstein [5].

Em trabalho recente, Mutton et al. [6] avaliaram a influência da microestrutura sobre o desenvolvimento de fadiga de contato por rolamento em juntas soldadas de trilhos ferroviários perlíticos. As trincas por fadiga se nuclearam rapidamente nas bandas de esferoidização parcial nos dois lados da ZTA e se propagaram com maior taxa em relação às outras regiões das soldas obtidas por centelhamento elétrico. Deformação plástica severa nas regiões de dureza reduzida da ZTA foi apontada como a responsável pela nucleação precoce de trincas por fadiga. Os autores sugeriram investigações metalúrgicas de modo a correlacionar as condições de soldagem à esferoidização parcial da cementita, e apontam que há uma necessidade de maior conhecimento sobre os mecanismos que controlam o desenvolvimento microestrutural, de modo que parâmetros de soldagem mais adequados possam ser desenvolvidos.

Em outro trabalho sobre o tema, baseado nas medidas experimentais de temperaturas realizadas por Weingrill et al. [7], Porcaro et al. [8] realizaram estudos dilatométricos simulando os efeitos dos ciclos térmicos e do tamanho de grão austenítico sobre a morfologia da perlita e sua microdureza em correlação ao processo de soldagem elétrica por centelhamento de trilhos ferroviários. Os autores mostraram que a taxa de resfriamento poderia ser aumentada de modo a reduzir a esferoidização da perlita e manter maiores valores de dureza em todo o boleto soldado (o trilho ferroviário é formado por três regiões: boleto, parte superior na qual ocorre o contato roda-trilho; alma, parte central do trilho; e patim, parte inferior que se apoia sobre os dormentes). Dentre as possibilidades citadas para se modificar o processo de soldagem FBW, Porcaro et al. [8] citam a redução do número de passes de pré-aquecimento, como proposto em Micenko et al. [4] e Jilabi [9], de modo a se obter uma ZTA estreita.

Mutton et al. [6], alertam que a adoção de procedimentos que proporcionem a formação de ZTA estreita na soldagem elétrica por centelhamento de trilhos ferroviários pode aumentar de modo significativo o nível de tensões residuais presentes nas juntas. Em trabalho recente, Porcaro et al. [10] mostraram que é significativo o nível de tensões residuais presentes em juntas de trilhos soldadas pelo processo FBW e desenvolveram um modelo numérico computacional para o estudo de tais tensões residuais.

Neste contexto, a partir de resultados previamente publicados de caracterização estrutural e mecânica de juntas soldadas [3] e do importante trabalho de monitoramento de ciclos térmicos realizado por Weingrill et al. [7], simulações em dilatômetro foram realizadas de modo a compreender a evolução microestrutural de aço perlítico submetido à soldagem por centelhamento elétrico em termos de transformação de fases, incluindo comparação às diversas regiões da ZTA. Além disso, a partir do modelo termomecânico apresentado e validado em artigo anterior [10], pela primeira vez na literatura, os efeitos quantitativos da adoção de ZTA estreita sobre as tensões residuais foram simulados para a soldagem FBW de trilhos ferroviários.

\section{Materiais e Métodos}

\subsection{Materiais}

O material utilizado no estudo é um aço para trilhos ferroviários do tipo intermediário que atende à Norma AREMA (2013) [11] com perfil TR-57, ou seja, com densidade linear de aproximadamente $57 \mathrm{~kg} / \mathrm{m}$. Os requisitos de propriedades mecânicas, resultados de análise química e ensaios mecânicos podem ser consultados em [3,10].

\subsection{Ensaios de dilatometria}

Os corpos de prova para os ensaios dilatométricos foram usinados no sentido longitudinal do trilho, fora da região soldada e a $10 \mathrm{~mm}$ abaixo da superfície de rolamento do boleto. Os corpos de prova possuem seção cilíndrica com $3 \mathrm{~mm}$ de diâmetro e $10 \mathrm{~mm}$ de comprimento. Os ensaios foram realizados em um dilatômetro R.I.T.A. L78 do (Laboratório de Tratamentos Térmicos e Metalografia - LTM/UFOP), com aquecimento por indução e fluxo de gás hélio.

Considerando os resultados de ciclos térmicos experimentais de Weingrill et al. [7], juntamente com a caracterização estrutural da perlita e propriedades mecânicas em toda a ZTA para o mesmo aço [3], dois grupos de ensaios de dilatometria foram realizados, conforme mostrado na Figura 1.

Grupo (i), diagrama de transformação em resfriamento contínuo (TRC) do metal base: utilizou-se uma taxa de aquecimento de $5^{\circ} \mathrm{C} / \mathrm{s}$ e temperatura de austenitização igual a $900^{\circ} \mathrm{C}$ por $60 \mathrm{~s}$, condições estas que minimizam o efeito de crescimento de grão. Grupo (ii), diagrama TRC para a região de crescimento de grão da ZTA: utilizou-se uma taxa de aquecimento de $5^{\circ} \mathrm{C} / \mathrm{s}$ até $900^{\circ} \mathrm{C}$, depois, uma taxa de aquecimento de $100^{\circ} \mathrm{C} / \mathrm{s}$ até a temperatura de austenitização de $1300^{\circ} \mathrm{C}$ por $1 \mathrm{~s}$. O grupo (ii) foi usado para simular a região de crescimento de grãos da ZTA e obter o diagrama TRC com maior tamanho de grão austenítico. Nos dois casos, a temperatura inicial de resfriamento para decomposição da austenita foi igual a $900^{\circ} \mathrm{C}$ e as taxas de resfriamento podem ser observadas na Figura 1.

A taxa de aquecimento igual a $5^{\circ} \mathrm{C} / \mathrm{s}$ até a temperatura de $900^{\circ} \mathrm{C}$ foi definida a partir de trabalhos previamente publicados [7]. Ressalta-se que o processo FBW apresenta aquecimento mais lento que os processos de soldagem a arco, pois há um período relativamente longo de pré-aquecimento. A utilização das duas taxas de aquecimento no Grupo (ii) se fez necessário para controlar o crescimento de grão austenítico em temperaturas acima de $900^{\circ} \mathrm{C}$ (definido a partir de ensaios exploratórios). 


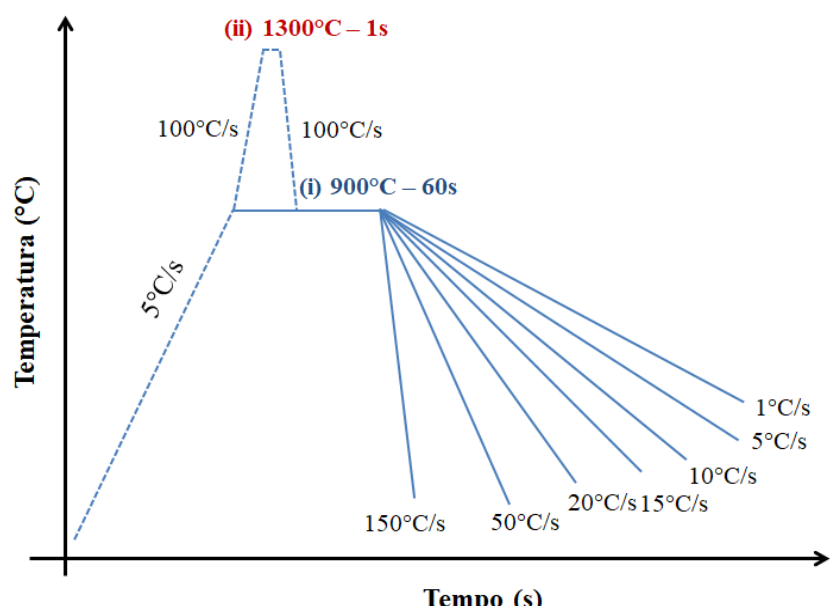

Figura 1. Ciclos térmicos aplicados em corpos de prova do metal base em ensaios de dilatometria, aço perlítico para trilhos. (i) Austenitização a $900^{\circ} \mathrm{C}(60 \mathrm{~s})$, usado para obter o diagrama TRC do metal base. (ii) Austenitização a $1300^{\circ} \mathrm{C}$ (1s), usado para avaliar o efeito do tamanho de grão austenítico na transformação de fases (ZTA).

Os dados obtidos nos ensaios de dilatometria foram tratados no software Origin ${ }^{\circledR}$ para determinação das temperaturas críticas no aquecimento e resfriamento, a metodologia empregada foi o método do desvio mínimo [12]. Todas as amostras de dilatometria foram submetidas a análise microestrutural após preparação metalográfica convencional e ataque com reativo Nital $2 \%$ de modo a confirmar os eventos dilatométricos. Além disso, foram realizadas medições de microdureza Vickers com 200gf de carga, em todas as amostras (15 medidas em cada caso).

Os corpos de prova de dilatometria submetidos à maior taxa de resfriamento $\left(150^{\circ} \mathrm{C} / \mathrm{s}\right)$ foram utilizados para medida de tamanho de grão austenítico prévio a partir de ataque com o reativo Picrato de Sódio. As análises foram realizadas em microscópio óptico e o processamento das imagens foi realizado no software LAZ, Leica versão 4.6, segundo a Norma ASTM E1382 (2015) [13]

Considerando-se a taxa de resfriamento de $1^{\circ} \mathrm{C} / \mathrm{s}$ como representativa do processo de soldagem aplicado ao trilho, as amostras dilatométricas dos grupos (i) e (ii) resfriadas a esta taxa passaram por caracterização semelhante àquela realizada no boleto soldado [3], incluindo oxidação parcial para medir tamanho de colônias perlíticas e medidas de espaçamento interlamelar em Microscópio Eletrônico de Varredura (MEV). Com isso, pôde-se demonstrar como o tamanho de grão austenítico prévio influencia a morfologia da perlita e as propriedades mecânicas em diferentes regiões da ZTA de trilhos soldados por centelhamento.

\subsection{Simulações numéricas por elementos finitos}

O desenvolvimento de tensões residuais durante o processo de soldagem elétrica por centelhamento foi simulado numericamente via Método dos Elementos Finitos. A primeira etapa das simulações foi o detalhamento do modelo 3D segundo a Norma AREMA (2013) [11]. Na Figura 2 apresenta-se o modelo, que possui simetria longitudinal, de modo a reduzir o número total de nós e, assim, o tempo computacional para as simulações. O modelo possui comprimento total igual a $260 \mathrm{~mm}$, e um estudo de refinamento da malha, não estruturada, formada por elementos tetraédricos, foi realizado a partir da convergência dos valores de tensões equivalentes de vonMises (variação menor que $5 \%$ a partir do aumento do número de nós) e minimização do erro na resposta estrutural. Uma vez que o modelo estático estrutural apresenta não linearidade mais significativa que o modelo térmico, o primeiro foi utilizado para o estudo de refinamento da malha. Como parâmetros de refinamento, após o estudo de refinamento, adotaram-se tamanho global da malha de $10 \mathrm{~mm}$ e, na região de interesse correspondente à solda, submetida a maior fluxo térmico e gradientes de tensões, um refinamento igual a $2 \mathrm{~mm}$, resultando em 52056 elementos e 77953 nós (Figura 2).

O estudo termomecânico deve levar em consideração a deformação plástica durante o aquecimento/resfriamento, ou seja, trata-se de um problema fisicamente não linear. Para uma correta avaliação das tensões e deformações, foi criado um novo material na biblioteca do software de simulação. As propriedades físicas do material relacionadas ao modelo térmico (condutividade térmica e capacidade térmica em função da temperatura) foram as mesmas utilizadas em Cai et al. [14]. Ressalta-se que a simulação não leva em consideração a fusão dos materiais, pois trata-se de processo de soldagem no estado sólido. Como reportado por Ma et al. [15], as transformações de fases exercem significativa influência sobre o estado final de tensões residuais em juntas de trilhos soldados por FBW, no entanto, aqueles autores consideraram a formação de martensita. Uma vez que as taxas de resfriamento reportadas para esse processo de soldagem são próximas a $1^{\circ} \mathrm{C} / \mathrm{s}$ [7] e somente perlita foi encontrada na caracterização estrutural das juntas [3,10], não foi considerado no modelo a transformação martensítica e/ou bainítica. Sendo assim, considerou-se um valor médio igual a $3 \times 10^{-5} /{ }^{\circ} \mathrm{C}$ para o coeficiente de expansão térmica instantâneo, calculado a partir da derivada da deformação relativa em ensaios de dilatometria aplicado ao material [8] e com auxílio do software Origin ${ }^{\circledR} 9$ [16]. 


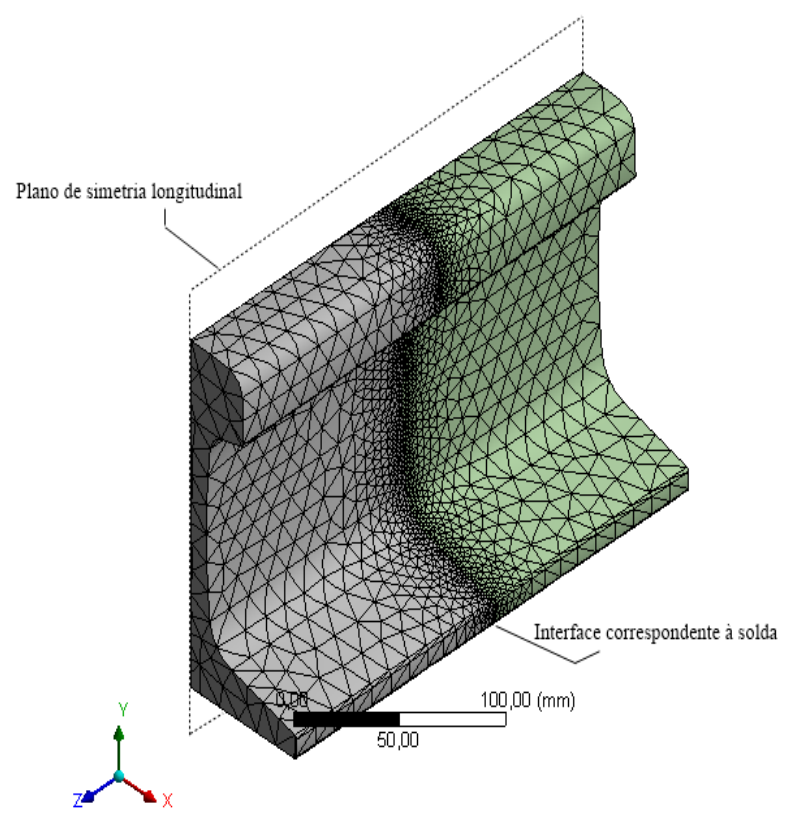

Figura 2 - Malha de elementos finitos adotada para trilho ferroviário com perfil TR-57 em simulações térmicas e estáticas estruturais.

Para considerar as propriedades mecânicas em função da temperatura foi utilizado o modelo bilinear isotropic hardening Ansys (2016) [17]. Os valores do módulo de elasticidade, limite de escoamento e módulo tangente foram os mesmos usados por Haibatollahi e Tehrani [18], pois o aço simulado por aqueles autores possui propriedades mecânicas próximas ao aço perlítico intermediário tratado neste trabalho.

\subsubsection{Modelo térmico}

A simulação térmica foi utilizada para obter a variação de temperatura (ciclo térmico) em cada nó do modelo, a partir da introdução de uma fonte de calor volumétrica entre os trilhos. Para determinar a resposta desse problema térmico no domínio do tempo, análise não-linear via elementos finitos foi realizada. Nesta, empregou-se o módulo Transient Thermal do software Ansys ${ }^{\circledR}$ e adotou-se o elemento finito 'SOLID 87' (tetraedro parabólico), com 10 nós por elemento [17].

Duas condições de aporte térmico foram adotadas de modo comparativo nos modelos: (i) modelo padrão, idêntico ao adotado na parte 1 deste trabalho [10] e validado por extensometria; neste caso, uma fonte de calor volumétrica de 30mm foi usada, Figura 3. (ii) Modelo com ZTA estreita, baseado nos trabalhos de Micenko et al. [4] e Jilabi [9], o elemento de aquecimento central foi reduzido para $24 \mathrm{~mm}$, de modo a simular o efeito da redução do número de pulsos de pré-aquecimento durante a soldagem FBW. Nos dois modelos, estabelecerem-se valores de geração de calor volumétrico iguais a $0,125 \mathrm{~W} / \mathrm{mm}$ para o boleto e patim, e iguais a $0,14 \mathrm{~W} / \mathrm{mm}^{3}$ para a alma, por 80 s. Além disso, como apresentado na parte 1 do trabalho [10], um aporte superficial igual a $1200 \mathrm{~W}$ foi aplicado durante os 80 s de aquecimento, Figura 3.
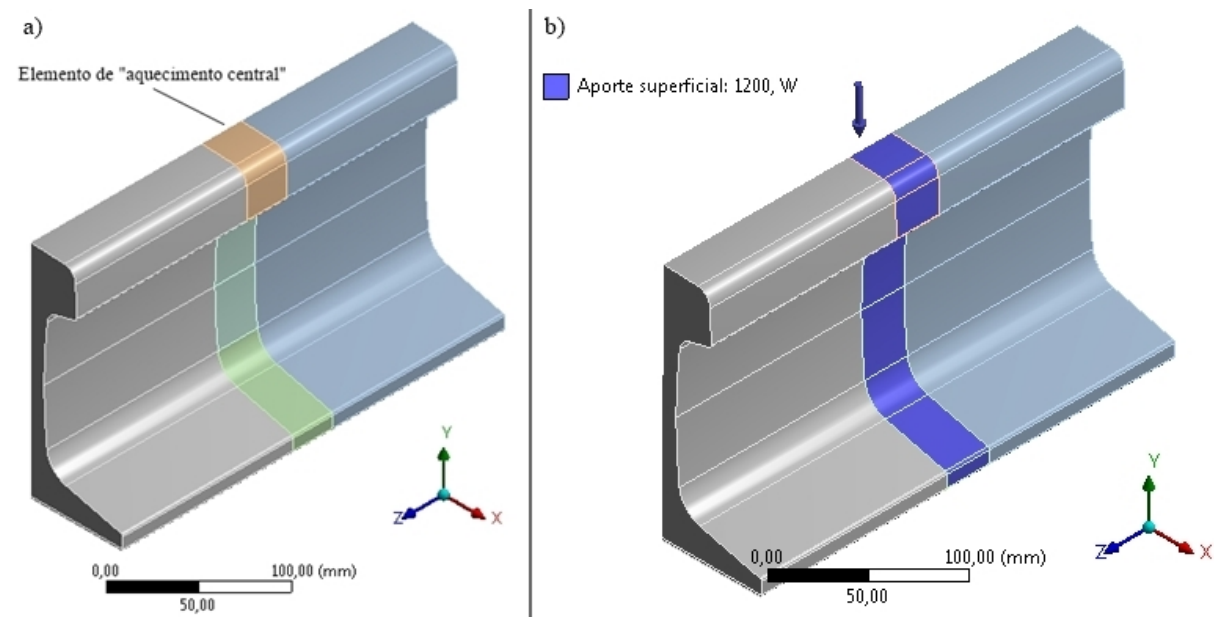

Figura 3. Representação em CAD da geometria do modelo do trilho ferroviário. (a) Em destaque um corpo intermediário, utilizado como elemento de aquecimento volumétrico. (b) Destaque para aporte de calor superficial. 
A partir da variação dos parâmetros dos dois modelos térmicos (modelo padrão e ZTA estreita), foi possível obter maiores taxas de resfriamento pós-soldagem, medida sugerida por Porcaro et al. [8] para reduzir os efeitos de esferoidização na ZTA.

Como condição inicial foi adotada temperatura uniforme igual a $25^{\circ} \mathrm{C} \mathrm{em} \mathrm{todo} \mathrm{o} \mathrm{modelo.} \mathrm{Também} \mathrm{foram} \mathrm{consideradas} \mathrm{as}$ perdas térmicas por radiação e convecção, sendo o coeficiente de convecção em função da temperatura igual ao reportado por Ma et al. [15]. Um modelo de radiação padrão do software foi usado para a simulação de radiação com temperatura ambiente igual a $25^{\circ} \mathrm{C}$ [17]. Mais detalhes sobre as condições de contorno são apresentados na parte 1 do trabalho [10].

\subsubsection{Modelo estático estrutural}

Os resultados de variação de temperatura em função do tempo em cada nó do modelo térmico foram utilizados como dados de entrada para o modelo mecânico no software Ansys ${ }^{\circledR}$, no módulo Static Structural. As condições de contorno do modelo são apresentadas na Figura 4. Os deslocamentos de todos os nós do plano $Y X$ foram restringidos nas direções $Z$ e $Y$, uma vez que durante a soldagem, 0 eletrodo fixo da máquina impede movimentos do trilho (plano $A$ da Figura 4). Os deslocamentos na direção $X$ no plano de simetria $Y Z$ também foram restringidos. Ressalta-se que a extremidade oposta ao plano A do modelo (Figura 4) possui todos os deslocamentos livres, pois corresponde ao trilho ligado ao eletrodo móvel durante o processo de soldagem por centelhamento. Também não se considerou a força de forjamento aplicada ao final da soldagem, estratégia comumente adotada em simulações de soldagem por centelhamento elétrico em função das dificuldades para sua consideração $[14,15,18]$.

O problema estático estrutural é fisicamente não-linear, e para a sua resolução via MEF, também empregou-se o software Ansys ${ }^{\circledR}$. De modo coerente com a análise térmica, adotou-se aqui, na análise elastoplástica 3D do sólido, o elemento finito 'SOLID 187' (tetraedro parabólico), com 10 nós por elemento [17].

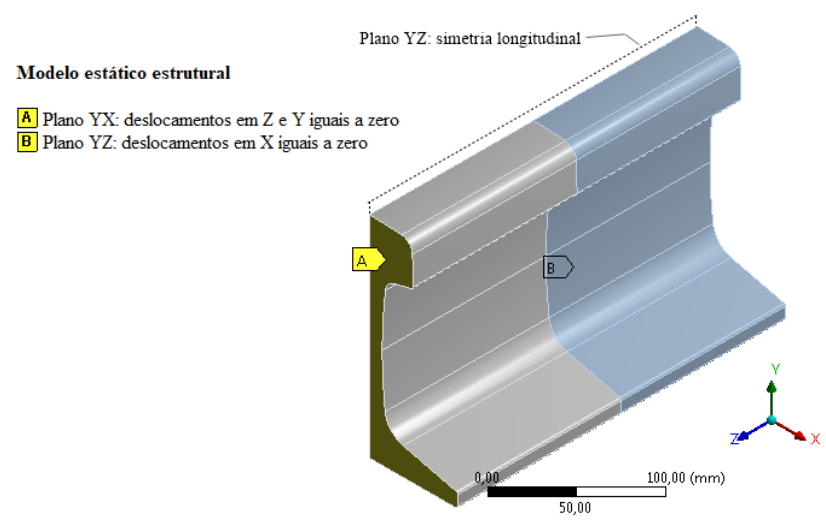

Figura 4. Condições de contorno para o modelo estático estrutural equivalente ao processo FBW.

\section{Resultados e Discussão}

\subsection{Dilatometria}

Os resultados dos ensaios de dilatometria do metal base (grupo (i)) sob diferentes taxas de resfriamento são apresentados na forma de diagrama TRC na Figura 5, para temperatura de austenitização igual a $900^{\circ} \mathrm{C}$.

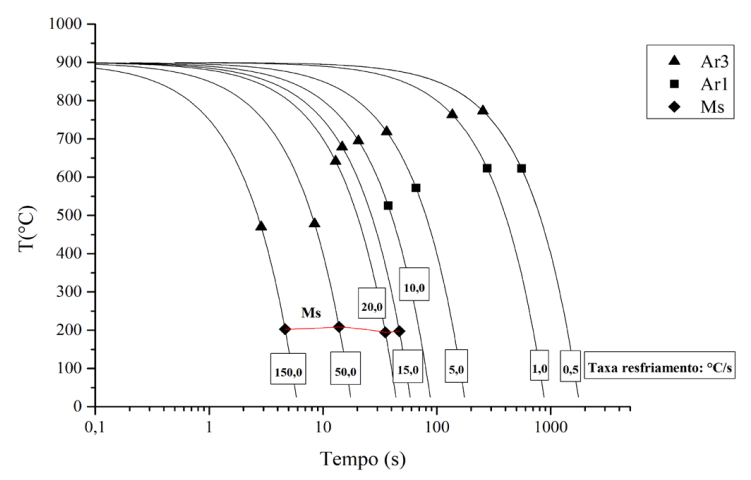

Figura 5. Diagrama de transformação sob resfriamento contínuo do metal base, aço perlítico intermediário para trilhos. Temperatura de austenitização igual a $900^{\circ} \mathrm{C}$. 
Micrografias de algumas amostras de dilatometria obtidas em microscópio óptico são apresentadas na Figura 6. Pode-se observar que para resfriamentos menores que $15^{\circ} \mathrm{C} / \mathrm{s}$ (Figuras $6 \mathrm{a}$ e b), somente perlita foi obtida, com diferentes morfologias, confirmando as indicações dilatométricas. Para taxas de resfriamento a partir de $15^{\circ} \mathrm{C} / \mathrm{s}$ (Figura $6 \mathrm{c}$ ), há início de formação de constituintes com mecanismo displacivo, neste caso, martensita. Para taxas de resfriamento entre $20^{\circ} \mathrm{C} / \mathrm{s}$ e $150^{\circ} \mathrm{C} / \mathrm{s}$, qualitativamente, a proporção de martensita aumenta continuamente nas micrografias, Figuras $6 \mathrm{~d}-\mathrm{f}$.

(a)
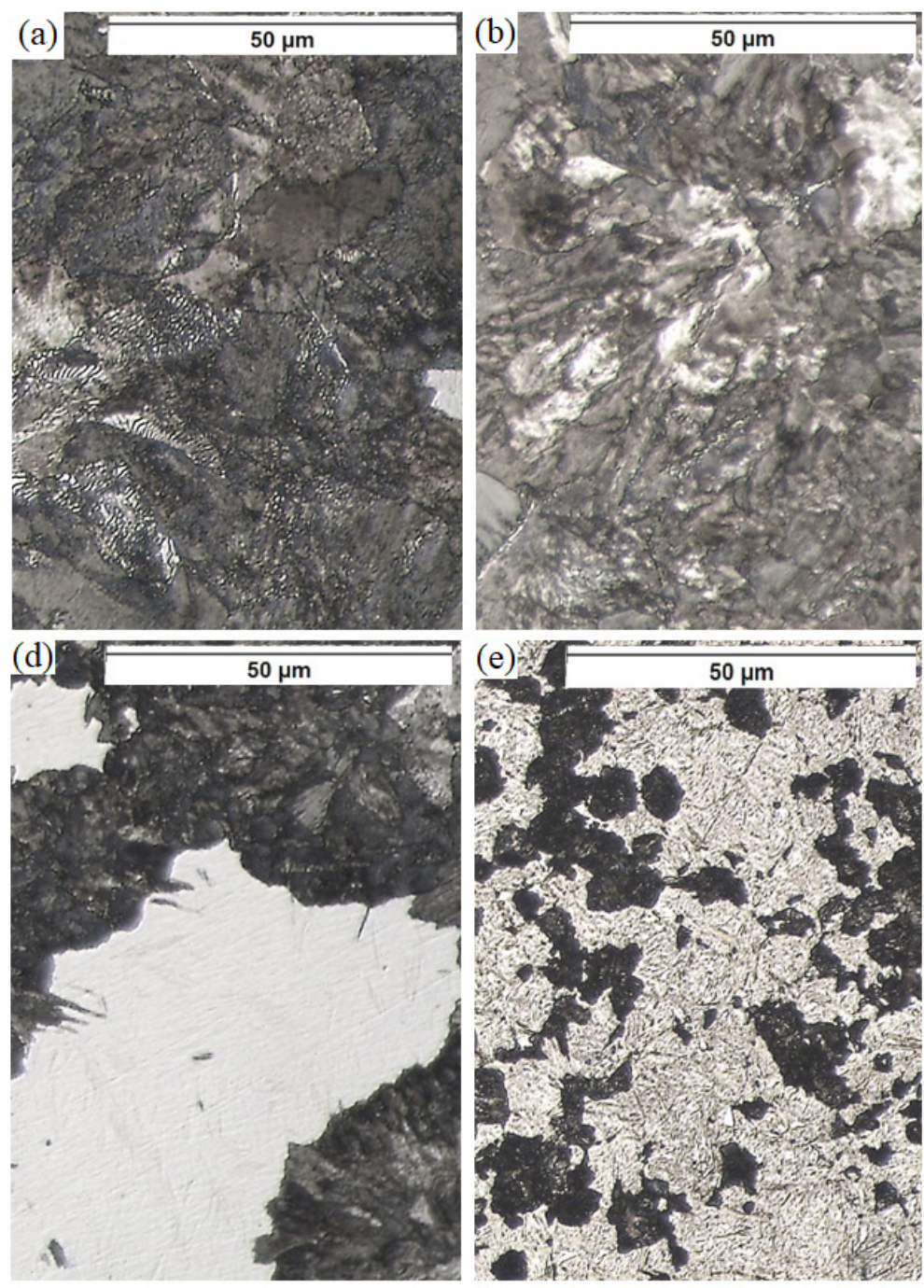
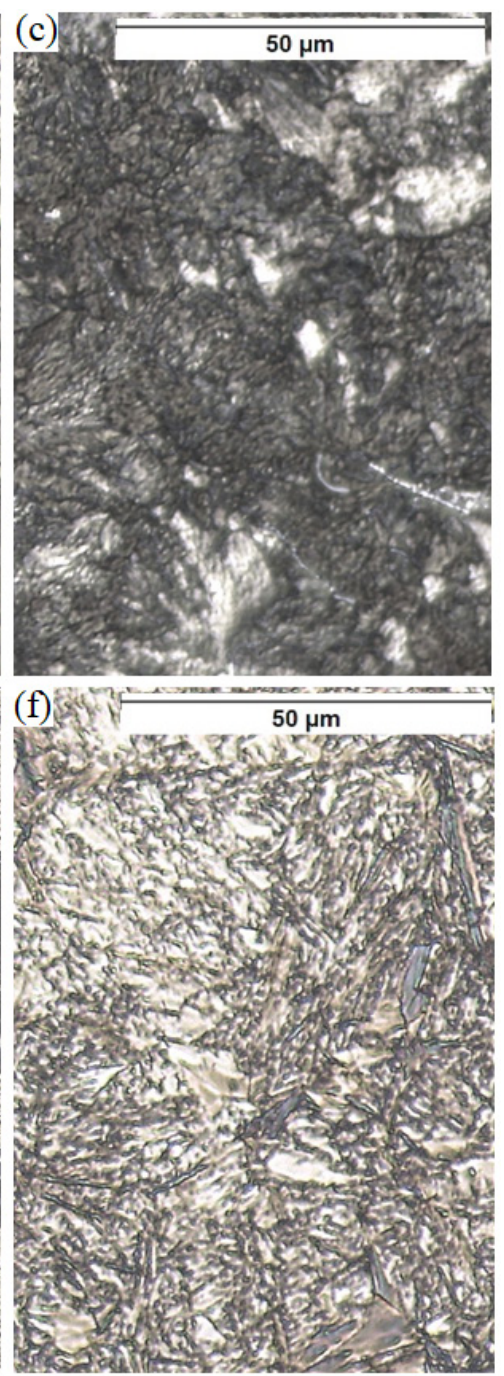

Figura 6. Micrografias obtidas em microscópio óptico de amostras de dilatometria do metal base para diferentes taxas de resfriamento: (a) $0,5^{\circ} \mathrm{C} / \mathrm{s}$; (b) $10^{\circ} \mathrm{C} / \mathrm{s}$; (c) $15^{\circ} \mathrm{C} / \mathrm{s}$; (d) $20^{\circ} \mathrm{C} / \mathrm{s}$; (e) $50^{\circ} \mathrm{C} / \mathrm{s}$ e (f) $150^{\circ} \mathrm{C} / \mathrm{s}$. Aumento original de $500 \mathrm{x}$, Nital $2 \%$.

A análise de tamanho de grão a partir da amostra austenitizada a $900^{\circ} \mathrm{C}$ e submetida à maior taxa de resfriamento $\left(150^{\circ} \mathrm{C} / \mathrm{s}\right)$ indicou um diâmetro médio equivalente de $27 \mu \mathrm{m}$ com desvio padrão igual a $15 \mu \mathrm{m}$.

Outro grupo de ensaios de dilatometria foi utilizado para simular a região de crescimento de grão da ZTA, Grupo (ii), com temperatura de austenitização igual a $1300^{\circ} \mathrm{C}$ por $1 \mathrm{~s}$. As análises de tamanho de grão austenítico prévio, neste caso, indicaram um diâmetro médio equivalente igual a $150 \mu \mathrm{m}$ com desvio padrão igual a $64 \mu \mathrm{m}$. Os efeitos do tamanho de grão austenítico na transformação de fases do material podem ser observados nos diagramas TRC sobrepostos da Figura 7, na qual se comparam os resultados dilatométricos dos grupos (i) e (ii). Além disso, também são apresentados os resultados de microdureza Vickers obtidos para os dois grupos.

Observa-se nos resultados dos diagramas TRC que a temperatura de pico e, consequentemente, o tamanho de grão austenítico prévio teve significativa influência nas temperaturas de transformação de fases da austenita durante o resfriamento contínuo do aço para trilhos e nos valores de microdureza Vickers. Outro ponto que merece destaque na Figura 7 é que para o maior tamanho de grão austenítico prévio (média de $150 \mu \mathrm{m}$ ), a partir da taxa de resfriamento igual a $10^{\circ} \mathrm{C} / \mathrm{s}$, já há transformação martensítica, por outro lado, para o menor tamanho de grão austenítico prévio (média de $27 \mu m$ ), transformação martensítica só ocorre para resfriamentos acima de $15^{\circ} \mathrm{C} / \mathrm{s}$. 


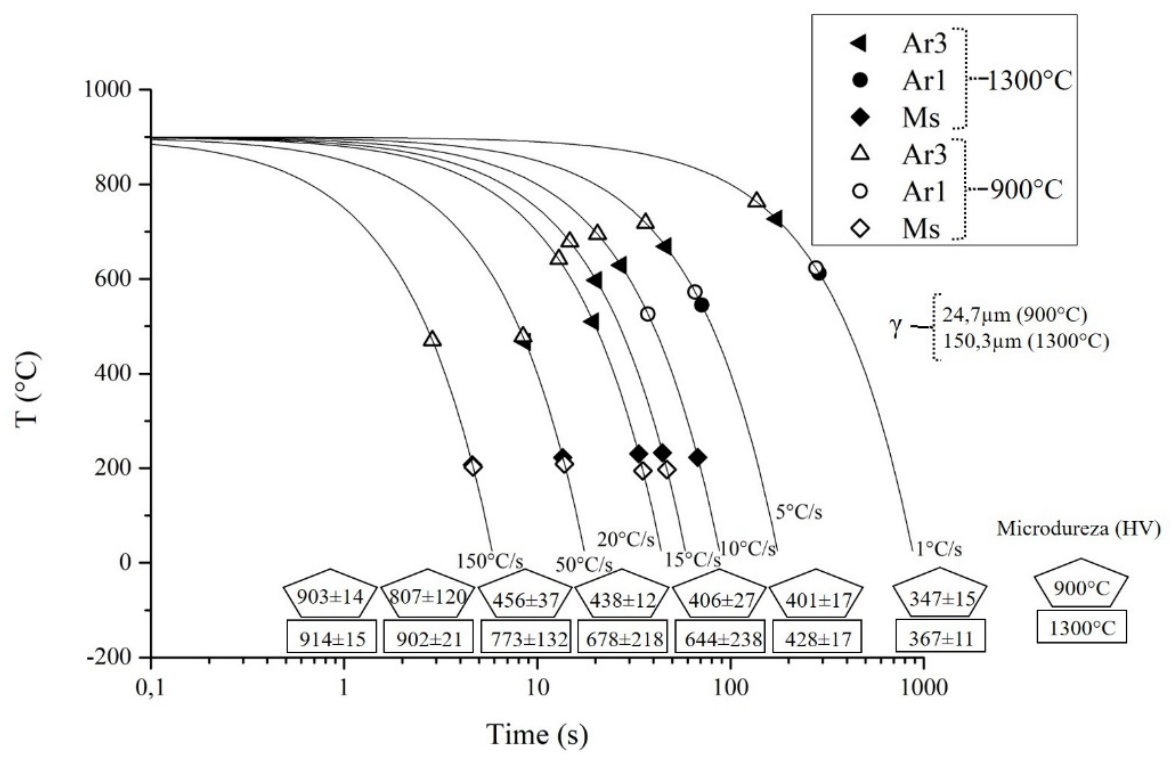

Figura 7. Diagramas de transformação sob resfriamento contínuo do metal base, aço perlítico intermediário para trilhos comparando duas diferentes temperaturas de austenitização e diferentes tamanhos de grão austenítico prévio. Apresentam-se ainda valores de microdureza Vickers com 200gf.

A taxa de resfriamento natural de juntas de trilhos ferroviários soldados por centelhamento é da ordem de $1^{\circ} \mathrm{C} / \mathrm{s}$ [7]. Saita et al. [19] e Tawfik et al. [20] relatam que existem alguns procedimentos que aplicam resfriamento acelerado com convecção forçada e/ou spray de água após a soldagem por centelhamento, visando o aumento de produtividade e a redução das diferenças de dureza nas regiões da ZTA. No entanto, Cai et al. [14] relatam que as taxas típicas de resfriamento após a soldagem por centelhamento ficam entre $1^{\circ} \mathrm{C} / \mathrm{s}$ e $10^{\circ} \mathrm{C} / \mathrm{s}$. A partir dos resultados apresentados na Figura 7 , fica claro que a escolha de taxas de resfriamento acelerado após a soldagem por centelhamento elétrico deve ser feita com cuidado e não pode basear-se somente no diagrama TRC do metal base, uma vez que o crescimento de grão pode aumentar significativamente a temperabilidade na ZTA.

Nas Figuras 8a e b são apresentados, de modo comparativo, os valores de tamanho de grão austenítico prévio, espaçamento interlamelar, tamanho de colônias perlíticas e microdureza Vickers para as amostras de dilatometria resfriadas a $1^{\circ} \mathrm{C} / \mathrm{s}$ e com diferentes temperaturas de austenitização, $900^{\circ} \mathrm{C}$ e $1300^{\circ} \mathrm{C}$, respectivamente.

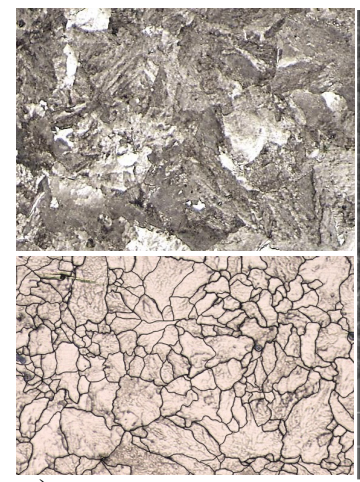

a) Dilatometria - Austenitizado a $900^{\circ} \mathrm{C}$ Taxa de resfriamento: $1^{\circ} \mathrm{C} / \mathrm{s}$

Tamanho de grão austenita: $27,4 \pm 14 \mu \mathrm{m}$ Tamanho de colônias perlíticas: $16,7 \pm 8 \mu \mathrm{m}$ Espaçamento perlita: $0,12 \pm 0,02 \mu \mathrm{m}$ Microdureza: $347 \pm 15 \mathrm{HV}$

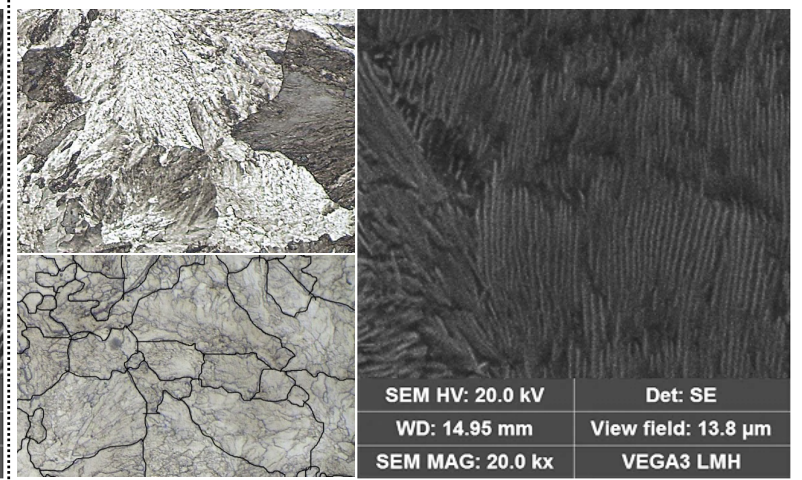

b) Dilatometria - Austenitizado a ${ }^{2300^{\circ}} \mathrm{C}$ (1s)

Taxa de resfriamento: $1{ }^{\circ} \mathrm{C} / \mathrm{s}$

Tamanho de grão austenita: $150,3 \pm 63 \mu \mathrm{m}$ Tamanho de colônias perlíticas: $29,0 \pm 14 \mu \mathrm{m}$ Espaçamento perlita: 0,09 $\pm 0,01 \mu \mathrm{m}$ Microdureza: $367 \pm 11 \mathrm{HV}$

Figura 8. Morfologia perlítica, tamanho de grão austenítico prévio e microdureza Vickers em amostras de dilatometria resfriadas a $1^{\circ} \mathrm{C} / \mathrm{s}$ e austenitizadas a diferentes temperaturas: (a) $900^{\circ} \mathrm{C} \mathrm{e} \mathrm{(b)} 1300^{\circ} \mathrm{C}$.

Os resultados apresentados das Figuras 7 e 8 corroboram a hipótese levantada em artigo anterior [3] sobre a formação da microestrutura na ZTA de trilhos de aços perlíticos soldados por centelhamento, ou seja, o menor espaçamento perlítico na 
região de crescimento de grãos em comparação à região de refino de grão se deve ao deslocamento (para baixo e direita) do diagrama TRC do aço. Como pode ser observado na Figura 8, para uma mesma taxa de resfriamento $\left(1^{\circ} \mathrm{C} / \mathrm{s}\right)$, a perlita originada a partir de austenita com maior tamanho de grão apresentou maior tamanho médio de colônias, mas menor espaçamento interlamelar e, portanto, maior dureza em comparação àquela originada de austenita com menor tamanho de grão. Em outras palavras, o aumento da temperabilidade associado ao crescimento de grão austenítico é o responsável por se observar perlita com lamelas mais finas na região de crescimento de grão da ZTA de juntas de trilho soldadas pelo processo FBW. Além disso, como demonstrado aqui, por meio de ensaios de dilatometria, o tamanho das colônias perlíticas originadas no resfriamento contínuo é proporcional ao tamanho da austenita prévia.

Jilabi [9] conduziu um grande trabalho de caracterização de ZTA em diferentes graus de trilhos ferroviários soldados por centelhamento. $\mathrm{O}$ autor obteve resultados semelhantes àqueles apresentados anteriormente [3], incluindo a variação de tamanho de colônias perlíticas em toda a junta e perfis de microdureza, com maior microdureza na região de crescimento de grão. No entanto, assim como no trabalho de Micenko et al. [4], os autores não conseguiram explicar os perfis de microdureza obtidos, sobretudo maior valor de dureza na região de crescimento de grão em relação à região de refino de grão. Micenko et al. [4] incluem em seu relatório a afirmação de que não há estudos na literatura utilizando dilatometria para entender a evolução microestrutural de trilhos de aços perlíticos soldados por centelhamento e que esse gap de conhecimento dificulta a melhoria do processo. O importante trabalho de Nishikawa e Goldenstein [5] foi o primeiro a aplicar dilatometria para simular a região de transformação parcial, no entanto, os autores não avaliaram as outras regiões da ZTA.

A partir dos resultados apresentados nesta seção, pode-se concluir que a taxa de resfriamento pós-soldagem natural para o aço avaliado foi da ordem de $1^{\circ} \mathrm{C} / \mathrm{s}$. Além disso, Porcaro et al. [3] mostraram que a taxa de resfriamento natural é superconservadora do ponto de vista de processo de soldagem, com significativa redução da dureza superficial no boleto devido à esferoidização parcial. De acordo com os resultados dilatométricos realizados no aço intermediário avaliado aqui, a taxa de resfriamento poderia ser aumentada para até $5^{\circ} \mathrm{C} / \mathrm{s}$ sem risco de formação de martensita mesmo na região de crescimento de grãos, ou seja, há uma janela de processo que pode ser utilizada sem aumento de custo/tempo de soldagem. Na próxima seção, a partir de simulações numéricas, os efeitos da adoção de ZTA estreita e da consequente maior taxa de resfriamento nas tensões residuais pós-soldagem são apresentados e discutidos.

\subsection{Simulações numéricas}

Os resultados do modelo térmico "ZTA estreita" em comparação ao modelo padrão simulado na parte 1 deste trabalho [10] são apresentados nas Figuras 9 e 10. Na Figura 9, pode-se observar que as temperaturas de pico foram muito próximas para os dois modelos na superfície do boleto, no entanto, como esperado, a taxa de resfriamento aumentou de maneira significativa $\left(50 \%\right.$ entre $800^{\circ} \mathrm{C}$ e $\left.500^{\circ} \mathrm{C}\right)$ com a simulação de um menor aporte de calor. Ressalta-se que a taxa de resfriamento de aproximadamente $4^{\circ} \mathrm{C} / \mathrm{s}$ obtida na condição ZTA estreita não seria suficiente para provocar formação de martensita no aço, conforme demonstrado nos ensaios de dilatometria apresentados na seção anterior. No entanto, como demonstrado por Porcaro et al. [8], o aumento da taxa de resfriamento é benéfico na redução da esferoidização parcial na região intercrítica da ZTA.

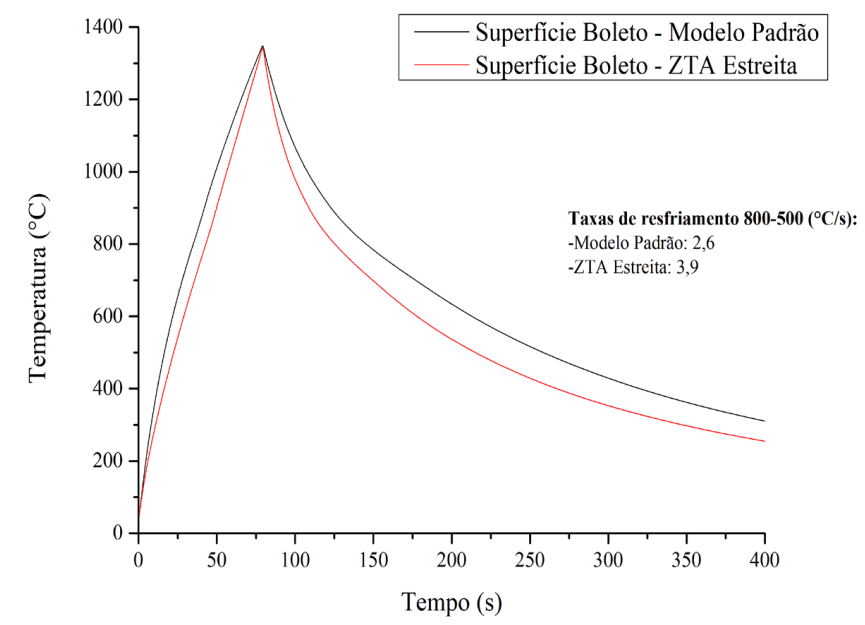

Figura 9. Ciclos térmicos monitorados em nó central na superfície de boleto nos dois modelos térmicos da soldagem elétrica por centelhamento de trilho ferroviário intermediário simulados: modelo padrão [10] e ZTA estreita.

Na Figura 10b apresenta-se um corte longitudinal do modelo ZTA estreita em comparação ao modelo padrão (Figura 10a). Pode-se observar que a adoção de um menor volume para o aquecimento resultou em redução da largura da ZTA em 
aproximadamente $14 \%$ na alma e $11 \%$ no boleto, respectivamente. Neste caso, considerou-se a largura da ZTA igual à temperatura aproximada de austenitização do aço $727^{\circ} \mathrm{C}[10]$.

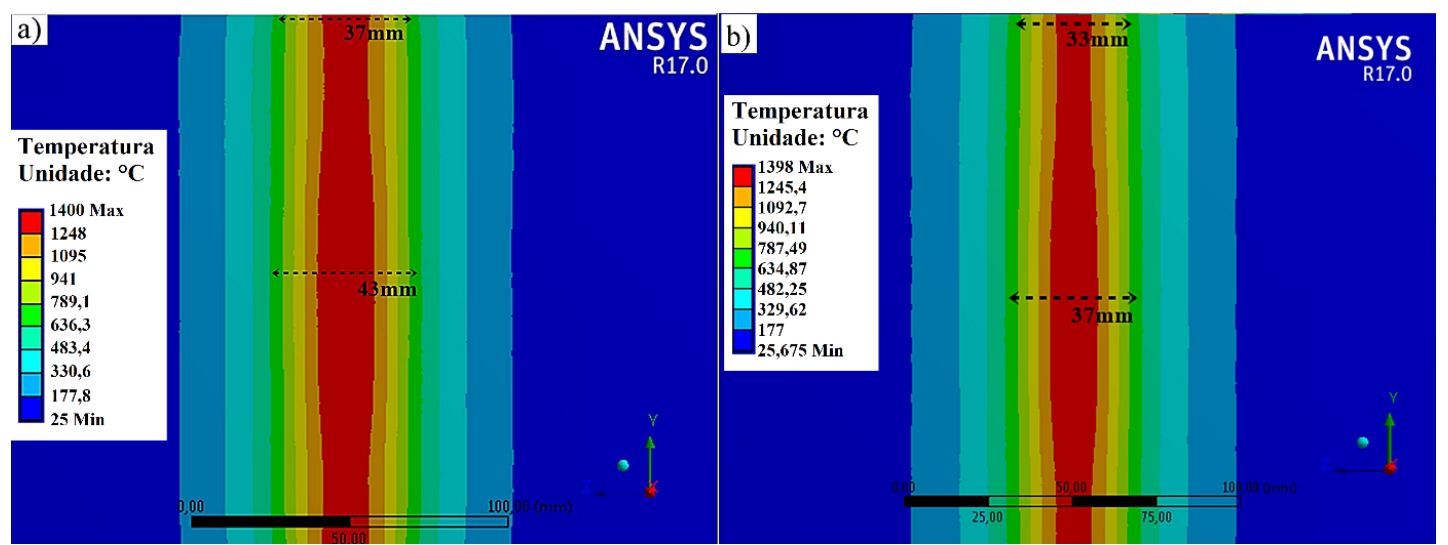

Figura 10. Comparação entre a largura da ZTA em corte longitudinal central nos dois modelos térmicos da soldagem elétrica por centelhamento de trilho ferroviário intermediário simulados: (a) modelo padrão [10] e (b) ZTA estreita. Temperaturas máximas durante as simulações.

Os resultados de tensões residuais normais para o modelo termomecânico da soldagem FBW com ZTA estreita são apresentados nas Figuras 11a e b, para os eixos Y e Z, respectivamente. Na Figura 11c, apresentam-se os resultados de tensões residuais normais em comparação aos resultados do modelo padrão e medidas experimentais apresentados na parte 1 deste trabalho [10]. Pode-se observar que os resultados do modelo com ZTA estreita apresentaram maiores valores de tensões residuais verticais em relação ao modelo padrão, média de $6 \%$ de aumento. No entanto, os maiores aumentos nos valores de tensões residuais normais no modelo ZTA estreita foram observados no sentido longitudinal, aumento médio de $17 \%$. Os aumentos nos valores de tensões residuais com a adoção de ZTA estreita podem ser atribuídos ao maior gradiente de temperatura obtido em relação ao modelo padrão [9].

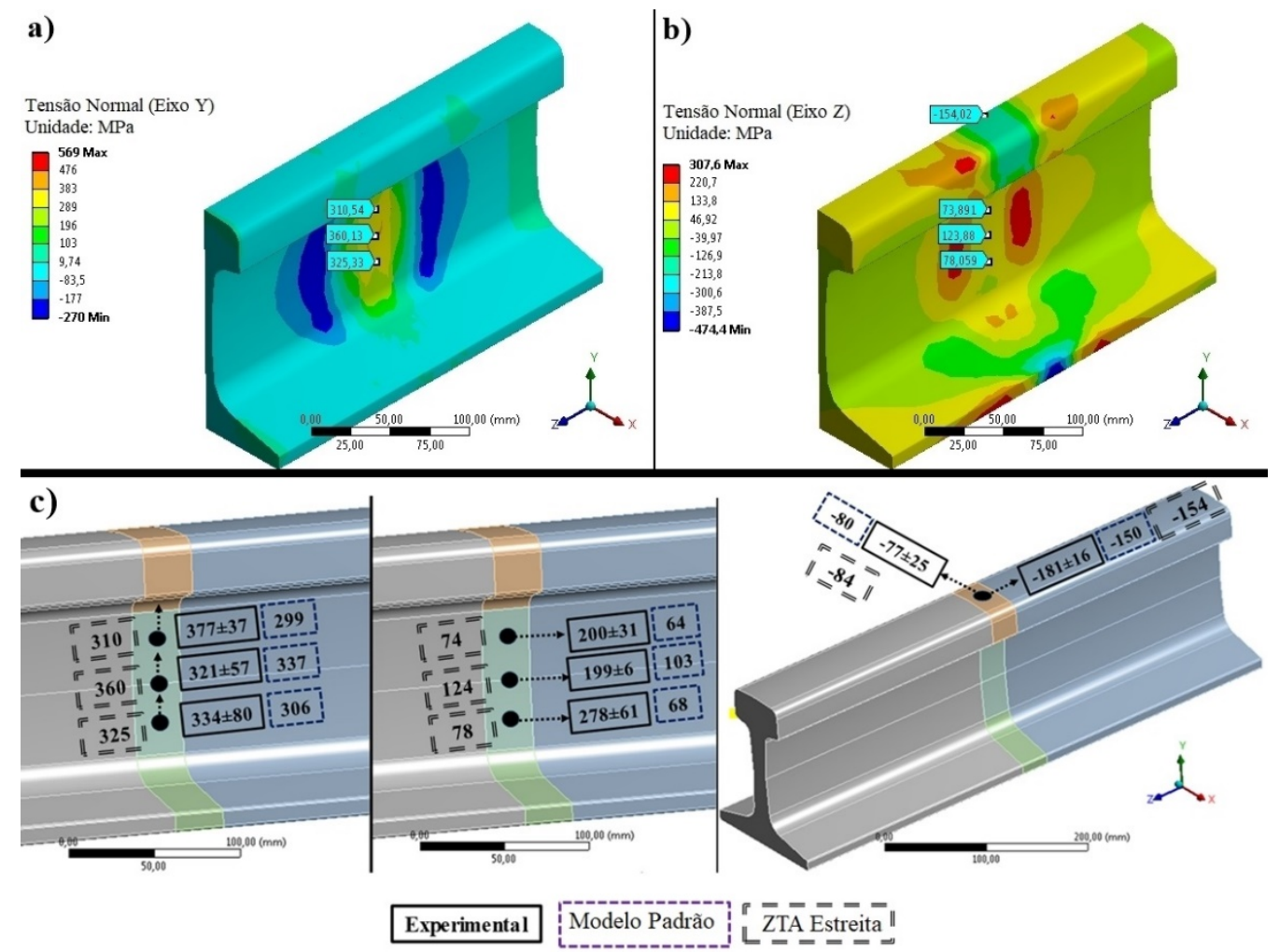

Figura 11. Tensões residuais normais na direção vertical (eixo Y) (a) e direção longitudinal (eixo Z) (b) obtidas por simulação numérica do processo de soldagem por centelhamento modelo ZTA estreita. Comparação entre os resultados de tensões residuais normais simuladas nas condições padrão e ZTA estreita e medidas experimentais (c) [10]. 
Micenko et al. [4] e Jilabi [9], sugerem a adoção de ZTA estreita na soldagem por centelhamento elétrico de trilhos ferroviários como uma medida para reduzir a variação de dureza no boleto. Mutton et al. [6] alertam que tal medida poderia resultar em aumento do nível de tensões residuais e, consequentemente, facilitar o processo de nucleação e crescimento de trincas por fadiga nas juntas, no entanto, os autores não apresentaram dados para sustentar essa hipótese.

Jilabi [9] realizou medidas de tensões residuais pelo método do contorno em trilhos ferroviários soldados pelo processo FBW com a adoção de ZTA estreita em comparação ao processo convencional. O autor reportou um aumento de $19 \%$ nos valores das tensões residuais longitudinais na condição ZTA estreita em relação ao procedimento convencional de soldagem. Em relação às tensões residuais verticais, por outro lado, não foram observadas variações significativas com a mudança dos parâmetros de soldagem. No entanto, o método utilizado pelo autor não permite comparação direta com outros trabalhos, que geralmente utilizam extensometria ou difração de nêutrons para medidas de tensões residuais em trilhos soldados.

Os resultados numéricos obtidos neste trabalho indicam que a adoção de ZTA estreita é uma maneira eficaz de aumentar a taxa de resfriamento pós-soldagem em trilhos ferroviários e, segundo estudo anterior [8], seria benéfico em relação à redução da esferoidização parcial da perlita e sua consequente perda de dureza. Segundo os resultados do modelo termomecânico apresentado aqui e um trabalho experimental anterior [9], as tensões residuais verticais na alma são pouco sensíveis à adoção de ZTA estreita. Esse resultado é muito significativo, pois componentes de tensões residuais normais verticais na região da alma são as mais importantes para explicar o desenvolvimento de fraturas por fadiga a partir da alma de juntas soldadas pelo processo FBW $[20,21]$. No entanto, ressalta-se que são necessários mais estudos experimentais para que os efeitos da adoção de ZTA estreita nas tensões residuais seja bem compreendido em juntas soldadas de trilhos ferroviários.

\section{Conclusões}

- O diagrama TRC da região de crescimento de grão foi deslocado para a direita e para baixo, representando aumento da temperabilidade quando comparado ao metal base, o que explica o menor espaçamento interlamelar perlítico na região de crescimento de grão em relação à região de refino de grão em soldas de trilho ferroviário perlítico obtidas por centelhamento elétrico;

- A região de crescimento de grão limita a máxima taxa de resfriamento pós-soldagem devido à sua maior temperabilidade. Ensaios de dilatometria indicaram que a taxa de resfriamento pós-soldagem atual do material é da ordem de $1^{\circ} \mathrm{C} / \mathrm{s}$, sendo possível ainda, de forma segura, o seu aumento até $5^{\circ} \mathrm{C} / \mathrm{s}$ sem a formação de martensita;

- Resultados de simulação numérica do processo de soldagem por centelhamento com adoção de ZTA estreita indicaram uma redução média de $11 \%$ na largura da ZTA e um aumento da taxa de resfriamento pós-soldagem igual a 50\% na superfície do boleto em comparação à soldagem com parâmetros padrão;

- As simulações termomecânicas do processo de soldagem FBW com ZTA estreita indicaram aumento das tensões residuais normais na alma da ordem de $6 \%$ no sentido vertical e de $17 \%$ no sentido longitudinal, em relação ao modelo do processo de soldagem padrão.

\section{Agradecimentos}

À Empresa VLI-FCA por ceder gentilmente as amostras e ao laboratório de microscopia eletrônica NanoLab - Redemat.

\section{Referências}

[1] Boer H, Masumoto H. Niobium in rail steel. In: Proceedings of the International Symposium, Niobium; Science \& Technology; 2001; Orlando, FL. Bridgeville: Minerals, Metals and Materials Society; 2001.

[2] Ordóñez Olivares R, Garcia Cl, DeArdo A, Kalay S, Robles Hernández FC. Advanced metallurgical alloy design and thermomechanical processing for rails steels for north american heavy haul use. Wear. 2011;271(1-2):364-373. http://dx.doi.org/10.1016/j.wear.2010.10.048.

[3] Porcaro RR, Lima DAP, Faria GL, Godefroid LB, Cândido LC. Microestrutura e propriedades mecânicas de um aço para trilhos ferroviários soldado por centelhamento. Soldagem e Inspeção. 2017;22(1):59-71. http://dx.doi.org/10.1590/0104-9224/si2201.07.

[4] Micenko P, Muruganant A, Huijun L, Xiaofeng X. Double dip hardness profiles in rail weld heat-affected zone: literature and research review report. Brisbane: CRC for Rail Innovation; 2013. Final Report, Project name: Improvements to Railway Welding.

[5] Nishikawa LP, Goldenstein H. Divorced eutectoid on heat-affected zone of welded pearlitic rails. JOM Journal of the Minerals, Metals \& Materials Society. 2018;70(11):1-9.

[6] Mutton P, Cookson J, Qiu C, Welsby D. Microstructural characterization of rolling contact fatigue damage in flashbutt welds. Wear. 2016;366-367:368-377. http://dx.doi.org/10.1016/j.wear.2016.03.020.

[7] Weingrill L, Krutzler J, Enzinger N. Temperature field evolution during flash butt welding of railway rails. Materials Science Forum. 2016;879:2088-2093. http://dx.doi.org/10.4028/www.scientific.net/MSF.879.2088. 
[8] Porcaro RR, Faria GL, Godefroid LB, Apolonio GR, Cândido LC, Pinto ES. Microstructure and mechanical properties of a flash butt welded pearlitic rail. Journal of Materials Processing Technology. 2019;270:20-27. http://dx.doi.org/10.1016/j.jmatprotec.2019.02.013.

[9] Jilabi ASJAZ. Welding of rail steels [doctor thesis]. Manchester: Faculty of Engineering and Physical Sciences, Manchester University; 2015.

[10] Porcaro RR, Araújo FC, Godefroid LB, Faria GL, Silva LL. Simulação do processo de soldagem elétrica por centelhamento de um aço para trilhos ferroviários. Parte 1: análise de tensões residuais via elementos finitos. Soldagem e Inspeção. 2019;24:e2412. http://dx.doi.org/10.1590/0104-9224/si24.12.

[11] American Railway Engineering and Maintenance-of-Way Association. Manual of railway engineering. Vol. 1. Maryland: AREMA; 2013. Rail; p. 695-965.

[12] García de Andrés C, Caballero FG, Capdevila C, Álvarez LF. Application of dilatometric analysis to the study of solid-solid phase transformations in steels. Materials Characterization. 2002;48(1):101-111. http://dx.doi.org/10.1016/S1044-5803(02)00259-0.

[13] American Society for Testing and Materials. E1382: standard test methods for determining average grain size using semiautomatic and automatic image analysis. West Conshohocken: ASTM; 2015. 24 p.

[14] Cai Z, Nawafune M, Ma N, Qu Y, Cao B, Murakawa H. Residual stresses in flash butt welded rail. Transactions of Joining and Welding Research Institute. 2011;40:79-87.

[15] Ma N, Cai Z, Huang H, Deng D, Murakawa H, Pan J. Investigation of welding residual stress in flash-butt joint of U71Mn rail steel by numerical simulation and experiment. Materials \& Design. 2015;88:1296-1309. http://dx.doi.org/10.1016/j.matdes.2015.08.124.

[16] Grishin A. Modeling thermal expansion in ansys [acesso em 16 jan. 2020]. Disponível em: https://www.padtinc.com/blog/wpcontent/uploads/2017/07/PADT-ANSYS-Secant_vs_Instantaneous_CTE-2017_07_05.pdf

[17] Ansys Inc. Product launcher release 17.0. ANSYS17.0 help. Canonsburg, Pensilvânia: Ansys Inc.; 2016.

[18] Haibatollahi SP, Tehrani PH. Prediction of residual stress distribution in flash butt welded rails using electro-thermo-mechanical simulation. International Journal of Vehicle Structures \& Systems. 2013;5(1):53-57. http://dx.doi.org/10.4273/ijvss.5.2.02.

[19] Saita K, Ueda M, Yamamoto T, Karimine K, Iwano K, Hiroguchi K. Trends in rail welding technologies and our future approach. Yawata: Nippon Steel \& Sumitomo; 2013. p. 84-92. (Nippon Steel \& Sumitomo Metal Technical Report; 105).

[20] Tawfik D, Mutton PJ, Chiu WK. Experimental and numerical investigations: alleviating tensile residual stress in flash-butt welds by localized rapid post-weld heat treatment. Journal of Materials Processing Technology. 2008;196(1-3):279-291. http://dx.doi.org/10.1016/j.jmatprotec.2007.05.055.

[21] Farhangi $\mathrm{H}$, Mousavizadeh SM. Horizontal split-web fractures of flash butt welded rails. In: Proceedings of the 8th International Fracture Conference; 2007; Istanbul, Turquia. Istanbul: Yildiz Technical University; 2007. p. 509-517. 